\title{
RAGAM BENTUK TINGGALAN BUDAYA MEGALITIK DI PAPUA (Variation of Megalithic Culture in Papua)
}

\author{
Erlin Novita Idje Djami \\ Balai Arkeologi Papua Jalan Isele, Kampung Waena, Distrik Heram, Kota Jayapura 99358 \\ Telepon (0967) 572467, Faksimile (0967) 572467 e-mail: novita_idje@yahoo.co.id
}

\section{INFO ARTIKEL}

\section{Histori artikel}

Diterima: 9 Februari 2016

Direvisi: 1 Maret 2016

Disetujui: 17 Mei 2016

\section{Keywords:}

megalithic culture,

the forms,

Papua

\section{Kata kunci:}

budaya megalitik,

bentuk,

Papua

\begin{abstract}
Papua is a place which is potential to have variety of cultural heritage of megalithic, and it spreads over the Papua. The megalithic tradition has been in this area since the prehistory period, even this it is continuing until today. The influence of this culture in Papua came from the west side through Sulawesi, Maluku and finally reached to Papua. Moreover, from the north side, it came through the Mikronesia area, Melanesia dan then arrived to Papua. The culture of megalithic is believed that it is influnced by the Austronesia people. The forms of megalithic in Papua include the terraces stone, mareuw, stone pole, ainining duka, mortar stone, sharpening stone, stone path, soul path, stone enclosure, megalithic archa, worning stone, throne stone, menhir (standing stone), table stone (dolmen), engraving stone, carving stone, totor, and turtle stone. This discovery of megalithic culture is related with the religious activity dan the other social cuture activities.
\end{abstract}

\begin{abstract}
ABSTRAK
Papua merupakan salah satu wilayah yang memiliki potensi keberadaan tinggalan budaya megalitik yang cukup banyak dan beragam bentuknya, lokasinya tersebar hampir di seluruh wilayah tersebut. Kehadiran tradisi megalitik di wilayah ini, sudah ada sejak zaman prasejarah, bahkan di beberapa tempat di Papua tradisi megalitik masih berlangsung hingga kini. Pengaruh budaya megalitik di wilayah Papua datang melalui dua jalur yaitu jalur barat melalui daerah Sulawesi, Maluku, hingga sampai ke Papua. Sedangkan jalur utara melalui wilayah Mikronesia, Melanesia, dan sampai ke Papua. Keberadaan budaya megalitik di Papua sebagai salah satu bentuk pengaruh dari bangsa Austronesia. Bentuk-bentuk tinggalan megalitik di wilayah Papua berupa bangunan berundak, mareuw, tiang batu, ainining duka, lumpang batu, batu asah, jajaran batu, jalan arwah, batu temugelang, arca megalitik, batu peringatan, tahta batu, menhir, dolmen, batu bergores, pahatan batu, totor, dan batu teteruga. Temuantemuan tinggalan budaya tradisi megalitik tersebut berkaitan erat dengan aktivitas religi dan aktivitas sosial budaya lainnya.
\end{abstract}

\section{PENDAHULUAN}

Menyikapi kehadiran budaya megalitik di Papua, ternyata memiliki sebaran yang cukup luas. Tidak hanya ditemukan di wilayah pesisir tetapi juga hingga di wilayah pegunungan tengah Papua. Megalitik merupakan suatu tradisi budaya yang diperkenalkan di Nusantara sekitar awal masehi, dan di beberapa daerah terus berlanjut ke zaman sejarah hingga sekarang (Simanjuntak, 2010: 57). Masyarakat pendukung budaya tersebut umumnya menghasilkan peralatan yang dibuat dari batu-batu besar yang digunakan dalam aktivitas sehari-hari (Sukendar, 1987:1).

Selain itu, ada juga pemanfaatan objek batu-batu yang berukuran lebih kecil maupun penggunaan bahan lain seperti kayu, apabila benda-benda tersebut jelas dipergunakan untuk tujuan sakral tertentu. Oleh karena itu, dapat dikatakan bahwa tradisi megalitik bukan hanya mengarah pada suatu bangunan batu besar tetapi lebih pada 
suatu konsep kepercayaan, karena orang dapat melakukan upacara megalitik tanpa harus didukung sarana upacara (Wagner, 1962: 72 dalam Soejono dan Leirissa, 2010: 250). Dalam konsep kepercayaan megalitik selain dalam konteks hubungan dengan pemujaan terhadap nenek moyang (Wagner, 1959:23-25 dalam Prasetyo, 2015: 15-16), juga kepada kekuatan-kekuatan alam yang dahsyat (Sutaba, 2008: 90).

Kehadiran budaya megalitik di Indonesia tidak terlepas dari keberadaan bangsa Austronesia yang pada masa neolitik (bercocok tanam) dan pada masa perunggu besi telah melakukan migrasi hingga ke Jepang, Formosa/Taiwan, Malaysia, Indonesia, bahkan ke Pasifik. Sejalan dengan migrasi bangsa Austronesia tersebut, telah menyebabkan tersebarnya tradisi megalitik di daerah-daerah yang dilaluinya (Prasetyo, dkk, 2004: 96-97). Di Indonesia keberadaan tradisi megalitik hampir menjangkau seluruh kepulauan ini, serta memiliki persamaan dengan tradisi megalitik di Asia Tenggara, Pasifik dan Oceania (Bellwood, 1978; Kim, 1982 dalam Sutaba, 2008: 90), dan salah satu wilayah di Indonesia yang kaya dengan budaya megalitik adalah wilayah Papua.

Kehadiran objek budaya megalitik di Papua, sangat menarik untuk dikaji lebih mendalam, baik itu yang terkait dengan bentuk, fungsi, maupun persebarannya. Karena jika ditinjau berdasarkan teori tentang masuknya budaya megalitik ke wilayah Papua dikatakan berasal dari Asia yang melalui dua jurusan, yaitu: pertama, melalui kepulauan Indonesia sebelah selatan dan berakhir di Maluku, namun pengaruhnya sampai ke Papua di sebelah utara hingga ke sungai Mamberamo, sedangkan di sebelah selatan pengaruh tersebut sampai di daerah pesisir selatan Papua (Kaimana dan sekitarnya) yang terletak di seberang kepulauan Kei dan Aru, tempat-tempat berakhirnya kebudayaan megalitik tersebut. Kedua, pengaruh megalitik di Papua berasal dari suatu daerah yang terletak antara kepulauan Taiwan (Formosa), Philipina, dan Sulawesi Utara yang menyebar ke Mikronesia dan kemudian menyebar terus ke New Guinea melalui kepulauan Admiralty yang terletak di utara Papua New Guinea. Di Papua New Guinea kebudayaan tersebut masuk melalui daerah Monumbo yang terletak di pantai utara Papua New Guinea. Pengaruh ke arah barat, yang akhirnya sampai ke Irian Jaya terjadi melalui dua jurusan. Jurusan pertama melalui pantai utara ke arah barat, mulai dari Monumbo ke kepulauan Schouten sampai ke sejauh Pulau Waigeo, kemudian kembali ke pesisir daratan New Guinea sepanjang muara Sungai Sepik, pantai Oinake, Sungai Tami, Sae (Skow-Mambo), Teluk Humboldt (Yos Sudarso), Nafri, dan Danau Sentani. Jurusan kedua masuk melalui Sungai Sepik dan menyeberang melalui pegunungan tengah menuju ke arah selatan sejauh pantai selatan New Guinea lewat sungai Fly, dan dari sana bergerak ke arah barat melalui Sungai Yawin, Sungai Kurkari, Sungai Siwasiv, Sungai Kayakai, Sungai Maro, dan Sungai Kumbe. Dua sungai terakhir tersebut terdapat di Papua. Melalui kedua sungai tersebutlah pengaruh kebudayaan megalit terus sampai ke daerah pedalaman, pada kebudayaan Yee-anim (Riesenfeld, 1950: 668-670; Mansoben, 1995: 64-65).

Terkait dengan teori tersebut dan pada kenyataannya, diketahui bahwa di wilayah Papua ada banyak ditemukan tinggalan budaya megalitik, dan jika dilihat dari beberapa laporan hasil penelitian arkeologi di wilayah Papua, diketahui bahwa keberadaan tinggalan megalitik di wilayah ini tidak hanya 
berada di daerah pesisir pantai, tetapi juga mencapai daerah pedalaman maupun pegunungan tengah Papua. Adapun bentuk-bentuk tinggalan megalitik di Papua cukup bervariasi, ada yang merupakan benda hasil karya atau buatan manusia, ada yang berupa benda bentukan alam yang tersentuh budaya, dan ada pula yang hanya berupa konsep kepercayaan tanpa suatu media tertentu. Dari ketiga bentuk tinggalan budaya tersebut, yang akan diuraikan terutama tentang tinggalan megalitik yang berupa benda materialnya.

Penelitian tentang bentuk dan sebaran megalitik di wilayah Papua menggunakan metode pendekatan kualitatif dengan bentuk penalaran induktif dan bersifat deskriptif analisis. Adapun teknik pengumpulan data dilakukan dengan studi kepustakaan dan observasi di lapangan. Seluruh data yang berhasil dihimpun dijadikan bahan analisis yang kemudian diinterpretasikan dan ditarik kesimpulan.

\section{PEMBAHASAN}

\section{Bentuk-Bentuk Tinggalan Budaya Megalitik di Papua}

\section{Punden Berudak/ Bangunan Berundak}

Punden berundak adalah bangunan berbentuk persegi konsentris yang ditemukan pada masa prasejarah di Indonesia dan juga di Pasifik. Umumnya bangunan ini memiliki pola atau bentuk memusat (konsentris) dengan bagian pusat tertinggi berada di tengah, dan pola memanjang yaitu dengan bagian pusat di belakang yang merupakan lokasi tertinggi (Susatyo, 1993:6-52).

Kehadiran punden berundak didasarkan pada keyakinan tentang kehidupan setelah mati, telah melahirkan suatu konsep tentang tempat bersemayamnya para arwah nenek moyang, antara lain di tempattempat tinggi seperti puncak gunung (Wales, 1958: 11), dan punden berundak merupakan refleksi dari daerah tinggi/gunung sebagai tempat bersemayamnya roh (Triwurjani, 2006: 39).

Temuan punden berundak di wilayah Papua berada di tiga tempat yaitu di Situs Srobu, Situs Pulau Brass dan di Situs Kali Raja. Temuan punden berundak di Situs Srobu, Kelurahan Abe Pantai, Distrik Abepura, Kota Jayapura adalah berupa bangunan berteras pola memanjang dengan tiga tingkatan, dan pada teras teratas terdapat menhir yang merupakan pusat tertinggi yang terletak di bagian belakang, karena punden berundak ini tersusun mengikuti kondisi permukaan bukit. Temuan punden berundak tersebut terkait dengan suatu aktivitas upacara pemujaan (Djami, 2015: 88).

Temuan bangunan berundak lainnya adalah di Situs Pulau Brass, Kampung Mapia, Kabupaten Supiori yaitu berupa temuan bangunan berundak bertingkat tiga dengan pola persegi dan memusat, dengan teras teratas berada di bagian tengah yang semakin tinggi dan lebih kecil dari teras ke dua maupun ketiga. Temuan bangunan berundak tersebut diindikasikan sebagai makam (Fairyo, 2013: 88), atau juga sebagai replika dari gunung karena pada area sekitar bangunan tersebut terdapat sejumlah kubur batu berbentuk persegi panjang yang mengitari bangunan berundak tersebut.

Selain itu, juga ditemukan sebuah bangunan berundak di Situs Kali Raja, Kampung Wawiyai, Kabupaten Raja Ampat yaitu berupa bangunan bertingkat tiga dengan pola persegi dan memusat, pada teras teratas berukuran lebih kecil dari teras ke dua maupun teras ke tiga. Pada teras ke dua di 
bagian depan dan belakang, masingmasing tertanam dua menhir penjaga yang ditutup dengan kain putih, dan pada teras teratas tempat diletakkan telur raja yang disimpan di atas susunan wadah yang terdiri dari gong di bagian bawah, kemudian beberapa susunan piring keramik, dan telur (batu lonjong) yang diletakkan di dalam piring teratas yang dibungkus dengan kain putih. Pada bagian undakan yang terdapat telur raja telah diberi kelambu sebagai penutup dan payung di atasnya. Objek bangunan berundak di Situs Kali Raja ini masih difungsikan sampai sekarang dalam ritual pemandian telur raja. Pada area bangunan berudak ini telah diberi bangunan pelindung berbentuk joglo.

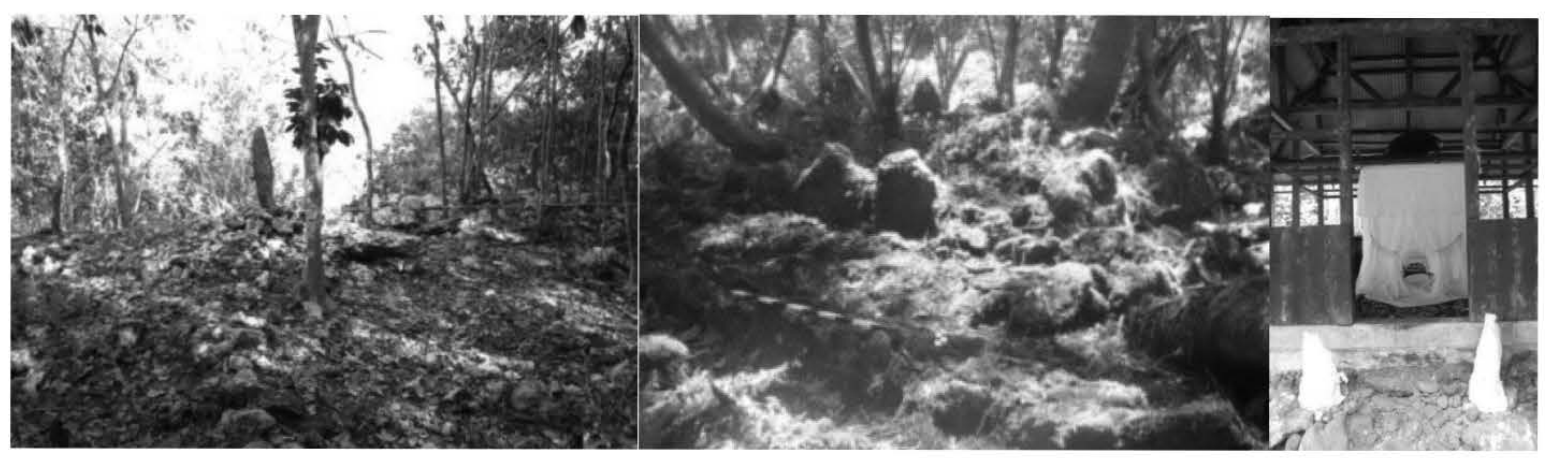

Gambar 1. Bangunan Berundak di Gunung Srobu, Situs Pulau Brass dan Situs Kali Raja (dokumentasi Balai Arkeologi Jayapura)

\section{Marew (Batu Rejeki)}

Mareuw adalah sebuah bongkah batu besar (batu alam) yang tertanam di pesisir Pulau Mantai, Danau Sentani, Kampung Kwadeware, Distrik Waibu, Kabupaten Jayapura. Marew ini dipercaya sebagai batu rejeki atau batu pembawa berkat, sehingga apabila ada orang yang hendak mencari makan, apakah itu mencari ikan di danau maupun berburu di hutan, biasanya terlebih dahulu mereka datang membawa sesajen dan meletakkan ke atas batu tersebut dengan tujuan memohon berkat keberhasil ketika mencari makan. Di samping itu, mereka juga meyakini apabila dalam suatu aktivitas mencari makanan dan mereka tidak memberikan sesajen pada mareuw, maka mereka akan mendapat sial atau tidak berhasil, hal ini terjadi karena kemarahan batu tersebut. Sehingga untuk meredakan amarah Mareu, maka mereka harus memberikan sesajen agar mereka murah rejeki kembali (Tim Peneliti, 2010:

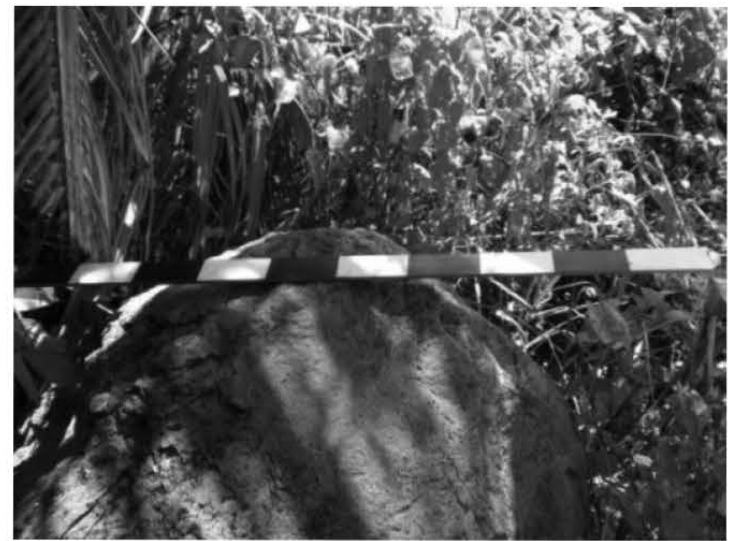

Gambar 2. Mareu atau batu rejeki (dokumentasi Balai Arkeologi Jayapura)

\section{Tiang Batu}

Temuan sebuah tiang batu di situs Pulau Asei, Kampung Asei, Distrik Sentani Timur, Kabupaten Jayapura adalah sebuah tiang batu penopang rumah atau umpak batu untuk rumah panggung. Tiang batu tersebut ditanam di dalam Danau Sentani dan tiang ini merupakan bekas tiang rumah adat yang telah terbakar pada waktu lampau. Temuan tiang rumah atau umpak batu tersebut, pada salah satu sisinya dibagian atas terdapat sebuah ukiran bermotif fouw yaitu motif pusat lingkaran yang melambangkan 
ondofolo sebagai pemegang kendali atas pemerintahan adat, dan setiap kegiatan maupun keputusan adat diatur oleh ondofolo yang kemudian dilaksanakan oleh semua lapisan masyarakatnya (Tim Peneliti, 2010: 26).

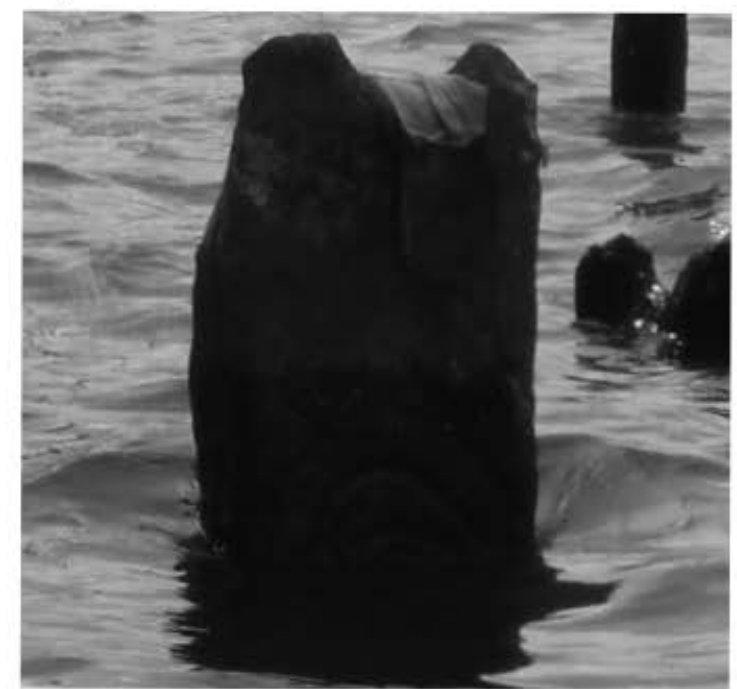

Gambar 3. Tlang betu bekas umpak rumah adat (dokumentasl Balal Arkeologl Jayapura

\section{Alnining Duka (Batu Beranak)}

Temuan batu beranak (ainining duka) di Danau Sentani, Kampung Kwadeware, Distrik Waibu, Kabupaten Jayapura adalah terdiri dari 12 buah batu yang tertanam dan tertata $\mathrm{dl}$ dalam danau. Batu-batu tersebut terdiri dari dua batu yang berukuran besar yang dianggap sebagai seorang lakilakj dewasa dan perempuan dewasa, sedangkan 10 batu berukuran kecil lainnya dianggap sebagai anakanaknya. Batu-batu tersebut akan tampak dengan jelas ketika air danau turun, dan ketika air danau penuh yang tampak hanya salah satu batu yang berukuran besar saja (laklaki), sedangkan yang lainnya tampak samar-samar dari permukaan air (Tim peneliti, 2010: 12). Kehadiran batu beranak tersebut dianggap sebagai lambang kesuburan dan keberhasilan.

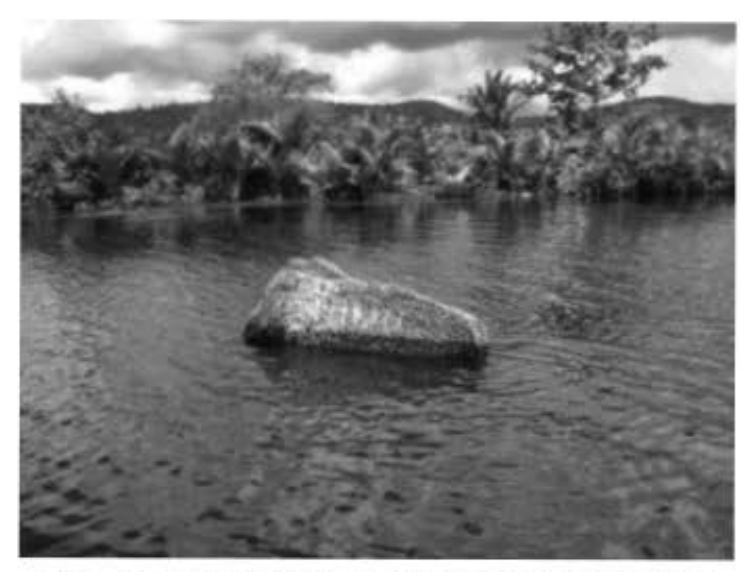

Gambar 4. Ainining duks (batu beranak) di Danau Sentani (dokumentasi Balai Arkeologi Jayapura)

\section{Merawal (Batu Sukun)}

Temuan batu sukun di Situs Kampung Tua Yasodia, DistrikDepapre, Kabupaten Jayapura yakni terdiri dari satu buah bongkah batu berukuran besar yang dianggap sebagai ibu yang melahirkan, dan terdapat satu arca menhir yang dianggap sebagai anak perempuan dan sembilan batu berbentuk bulat lonjong sebagai alas kepala, serta terdapat satu buah batu dakon yang telah pecah, namun pada permukaannya masih terlihat adanya tiga cekungan (Mene, 2013: 19).

Batu sukun ini (merawai) berfungsi sebagai sarana upacara untuk memanggil dan meminta berkat agar diberi kelimpahan buah sukun saat panen tiba. Upacara tersebut dilakukan dengan memandikan arca menhir yang diletakkan berdiri di atas batu ibu kemudian disirami air. Arr hasll pemandlan Inllah yang akan mengallr hingga kepohon-pohon sukun yang dimintal berkat hasil mellmpah. Pemandlan arca atau upacara batu sukun tersebut hanya bisa dilakukan oleh keluarga Yakarimilena sebagai pewaris batu sukun, dan untuk masyarakat lainnya dapat meminta berkat melalui keluarga bersangkutan untuk pohon sukun mereke. 


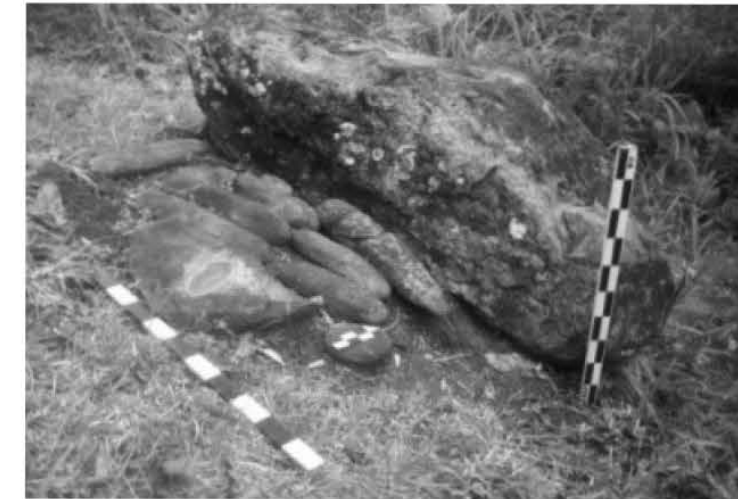

Gambar 5. Merawai (batu sukun) di Situs Kampung Tua Yasodia (dokumentasi Balai Arkeologi Jayapura)

\section{Lumpang batu}

Temuan lumpang batu di Situs Kampung Ayapo Baru, Distrik Heram, Kota Jayapura. Temuan empat buah lumpang batu dengan ukuran yang berbeda-beda. Lumpanglumpang batu tersebut merupakan batu-batu alam berukuran besar yang telah dilubangi permukaannya, ada yang hanya terdapat satu lubang berbentuk bulat, ada pula yang terdiri dari beberapa buah lubang, dengan kedalaman tiap lubang tidak sama. Menurut masyarakat lumpang batu tersebut berfungsi sebagai batu asah yang digunakan oleh nenek moyang mereka untuk mengasah kapak batu atau kapak lonjong (Suroto dkk, 2011: 24).

Selain itu juga ditemukan lumpang batu di Pulau Roon, Kampung Sariay, Kabupaten Teluk Wondama yaitu sebuah batu monolit yang disalah satu permukaannya berlubang. Lumpang batu ini dikenal dengan nama batu mawe atau batu permohonan. Batu mawe dipercaya oleh masyarakat sebagai batu yang dapat mengabulkan permohonan mereka, dan terkabulnya permohonan tersebut ditandai ketika seseorang mengangkat batu mawe dengan sangat ringan. Tetapi kalau batu tersebut terasa sangat berat ketika diangkat maka dapat dipastikan bahwa permohonannya tidak terkabulkan (wawancara Rini Maryone).

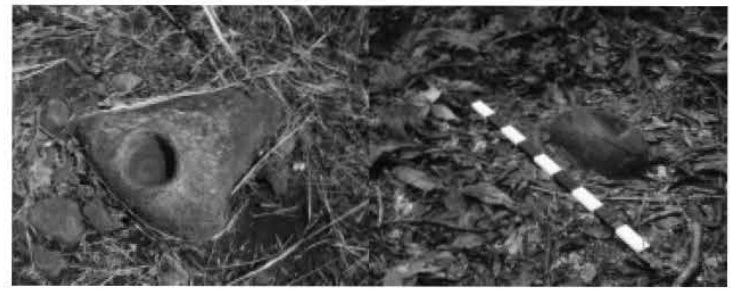

Gambar 6. Lumpang Batu di Situs Kampung Ayapo Baru dan Situs Kampung Sariay (dokumentasi Balai Arkeologi Jayapura)

\section{Batu Asah (Heleb Yage Matuke)}

Temuan batu asah (heleb yage matuke) di Situs Hitigima, Distrik Assotipo, Kabupaten Jayawijaya berjumlah enam buah yaitu berupa bongkah batu besar atau batu alam, yang pada bagian permukaannya dimanfaatkan untuk mengasah. Bekas aktivitas mengasah tersebut tampak pada permukaan batu berupa sejumlah cekungan-cekungan berbentuk lonjong. Batu-batu asah tersebut terdiri dari berbagai ukuran, dan semuanya ada bagian yang tertanam ke tanah. Letak batu asah berada dalam satu kompleks dengan batu tanda peringatan maupun susunan batu jalan arwah (Djami, 2015: 16).

Menurut masyarakat, dalam suatu pembuatan alat batu atau kapak batu hanya dapat dilakukan oleh orangorang tertentu saja, dan bahkan dalam pembuatnnya tidak boleh dilihat oleh orang lain. Dengan demikian dapat diasumsikan bahwa dalam proses pembuatan kapak batu terkait erat dengan suatu aktivitas religi.

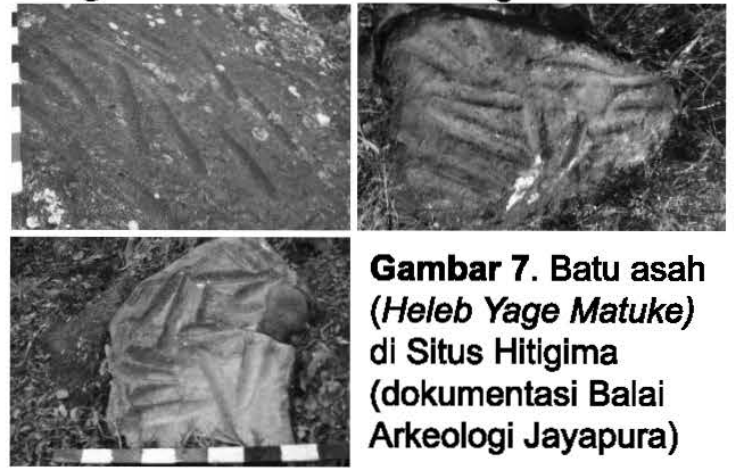




\section{Jajaran Batu}

Temuan Jajaran batu di Situs Megalitik Tutari, Kampung Doyo Lama, Distrik Waibu, Kabupaten Jayapura adalah berupa dua jajaran batu yang ditersusun berderat memanjang di atas permukaan tanah. Jajaran batu tersebut berada pada area yang menghubungkan antara kompleks lukisan batu dengan kompleks menhir yang terletak di puncak bukit. Kehadiran jajaran batu ini diasumsikan sebagai jalan penghubung menuju pusat ritual yaitu kompleks menhir. Namun demikian, jajaran batu tersebut menurut masyarakat adalah personifikasi dari para pahlawan yang gugur waktu perang suku di zaman dahulu (Prasetyo, 2001: 41).

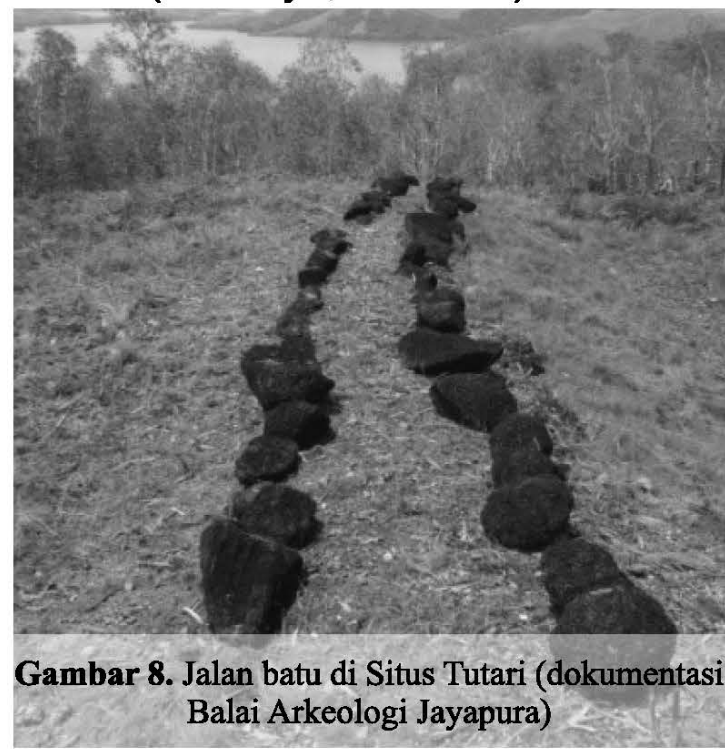

\section{Mokat Ake (Jalan Arwah)}

Mokat ake atau jalan arwah ditemukan di Situs Hitigima, Distrik Assotipo, Kabupaten Jayawijaya. Jalan arwah ini berupa susunansusunan batu dari berbagai ukuran yang ditata memanjang dan berbentuk seperti pagar batu. Jalan arwah ini memiliki panjang \pm 650 meter dari Kampung Asoma ke arah Wakunoak yang terletak di lereng gunung. Jalan arwah ini berfungsi sebagai jalan yang dilalui oleh arwah orang mati saat acara penghantaran arwah menuju ke Wakunoak, yaitu suatu tempat bersemayamnya roh-roh orang mati yang tinggal di sebuah gua yang berada di lerang Gunung Hesagenem. Penghantaran arwah tersebut dilakukan sebelum mayat dikremasi. Di samping jalan arwah tersebut, juga terdapat sejumlah tiang-tiang batu tempat melompatnya burung kiwiko ketika upacara penghantaran arwah dilakukan (Djami, 2015:17).

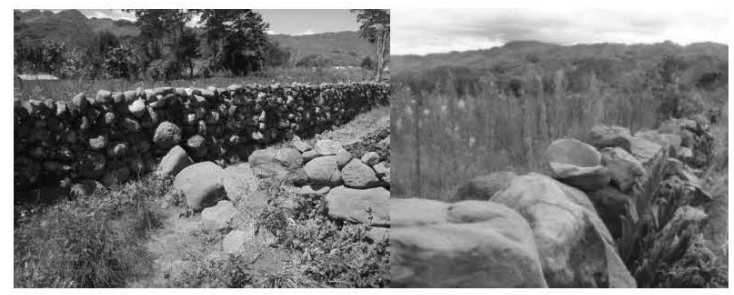

Gambar 9. Jalan Arwah (mokat ake) di Situs Hitigima (dokumentasi Balai Arkeologi Jayapura)

\section{Batu Temugelang}

Batu temugelang ditemukan di beberapa situs di wilayah Papua seperti di Situs Megalitik Tutari, Kampung Doyo Lama, Distrik Waibu, Kabupaten Jayapura. Temuan batu temugelang di situs ini berjumlah 8 buah, yang terdiri dari susunan batu berbentuk segi empat, susunan batu berbentuk melingkar tidak beraturan, dan susunan beberapa batu melingkar saling terkait. Batu-batu temugelang tersebut ada yang terletak di area datar yang berfungsi sebagai tempat ritual, dan ada pula yang berada di area tebing bukit yang berfungsi sebagai tempat pengintaian maupun pertahanan (Prasetyo, 2001: 20-42).

Selain itu di Situs Tutari, batu temugelang juga ditemukan di Situs Kocuata, Kampung Kokas, Distrik Aifat Barat, Kabupaten Maybrat, yaitu berupa sebuah teras yang terbentuk dari susunan batu berbentuk persegi yang berfungsi sebagai tempat menyelesaikan masalah-masalah adat (Fairyo, 2015: 11). 
Temuan batu temugelang lainnya adalah dari Situs Bukisi, Distrik Yokari, Kabuputen Jayapura yang berupa susunan berbentuk lingkaran sebanyak empat buah. Namun jumlah batu yang ada pada setiap susunan batu temugelang berbeda-beda, karena disesuaikan dengan fungsinya dan lokasi penempatannya menurut aturan adat. Misalnya batu temugelang yang terbentuk dari susunan lima buah batu, yang terletak di halaman rumah Marga Yarona, batu temugelang tersebut berfungsi sebagai tempat untuk membicarakan masalah-masalah adat di bidang ekonomi, sedangkan yang terdiri dari susunan tujuh buah batu, yang terletak di halaman rumah marga Yekari, berfungsi sebagai tempat untuk membicarakan masalahmasalah adat di bidang keamanan, dan batu temugelang yang terbentuk dari susunan 12 buah batu, yang terletak di halaman rumah marga Dewisa, berfungsi sebagai tempat untuk membicarakan masalahmasalah adat di bidang sosial-budaya, serta batu temugelang yang terbentuk dari susunan 17 buah batu, terletak di halaman rumah marga Andwatupu yang merupakan ondoafi, berfungsi sebagai tempat untuk membahas seluruh persoalan adat dan juga sebagai tempat pelantikan ondoafi. Pada setiap batu temugelang tersebut di bagian tengah lingkarannya terdapat perapian yang berfungsi sebagai penerang dan penghangat, karena pada waktu lampau pembicaraan masalah adat selalu dilakukan pada malam hari. Batu-batu temugelang tersebut masih difungsikan hingga kini. Sedangkan temuan batu temugelang di Situs Kampung Tua Kisidia, Kampung Yepase, Distrik Depapre, Kabupaten Jayapura adalah berupa sebuah batu monolit besar berbentuk setengah lingkaran lebih. Batu temugelang ini berfungsi sebagai tempat musyawara adat zaman dahulu (Mene, 2013: 1317).

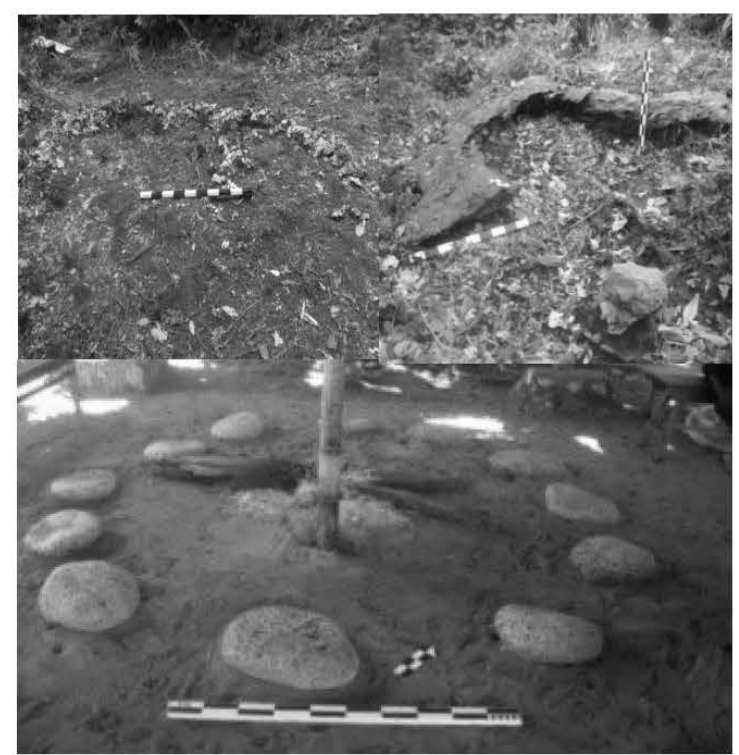

Gambar 10. Batu Temugelang di Situs Kocuata, Situs Bukisi, dan Situs Kisidia (dokumentasi Balai Arkeologi Jayapura)

\section{Arca Megalitik}

Temuan arca megalitik di wilayah Papua terdapat di beberapa situs seperti di Situs Kali Kubu Srum, Kampung, Klaisu, Distrik Gresi Selatan, Kabupaten Jayapura, telah ditemukan sebuah arca manusia yang terbuat dari bahan batu lempung berwarna kehijauan, arca yang ditemukan tersebut hanya bagian kepala hingga badannya karena telah patah, sedangkan bagian lainnya tidak ditemukan. Ukuran tinggi arca $56 \mathrm{~cm}$, lebar $27 \mathrm{~cm}$, dan berat $40 \mathrm{~kg}$. Arca tersebut memiliki bentuk wajah lonjong, dan terlihat menggunakan ikat kepala, serta berbadan besar. Temuan arca manusia lainnya adalah dari Situs Kampung Tua Yasodia, Distrik Depapre, Kabupaten Jayapura yaitu sebuah arca manusia yang terbuat dari jenis batu gneiss, arca ini memiliki kemiripan dengan arca dari Situs Kali Kubu Srum, namun bagian kepala arca lebih lonjong dan badannya lebih ramping. Ukuran tinggi arca $70 \mathrm{~cm}$ 
dan lebar $22 \mathrm{~cm}$. Arca tersebut berada dalam kelompok batu sukun atau batu beranak yang difungsikan sebagai sarana upacara dalam ritual untuk panen buah sukun (Mene, 2013: 19).

Selain itu juga ditemukan dua arca manusia lainnya dari Situs Kali Mimio, Kampung Uni, Distrik Bomakia, Kabupaten Boven Digoel. Temuan arca tersebut berada dalam keadaan basah dan rapuh. Arca ini terbuat dari bahan batu lempung yang dipahat berbentuk manusia berkepala besar dengan menggunakan penutup kepala berbentuk persegi, wajah arca lonjong dengan dagu panjang, badan ramping, perut menonjol, dan kaki cukup pendek. Arca tersebut memiliki ukuran tinggi $71 \mathrm{~cm}$, lebar $26 \mathrm{~cm}$, dan berat $30 \mathrm{~kg}$. Sedangkan arca yang berukuran kecil, yang tertinggal hanya bagian kepala dan sudah sangat aus (Kawer, 2014: 27-29).

Temuan arca manusia lainnya adalah dari Situs Srobu, Kelurahan Abe Pantai, DistrikAbepura, Kota Jayapura. Arca tersebut terbuat dari bahan batu pasir yang berbentuk pipih dan pada salah satu sisinya terpahat gambaran manusia bagian kepala hingga badan, tanpa tangan maupun kaki, dan tampak bagian bawah arca telah patah. Penggambaran arca tersebut memiliki bentuk wajah besar, tampak dua alis menonjol, mata bulat besar, bentuk hidung lebar, bibir tipis, di bawah bibir seperti berjanggut, dan bagian badan seperti menggunakan pakaian, serta arca tersebut memiliki ukuran tinggi $58 \mathrm{~cm}$ dan lebar $22 \mathrm{~cm}$. Secara umum bentuk-bentuk arca megalitik tersebut menunjukkan penggambaran yang lebih dinamis yaitu digambarkan lebih plastis (Prasetyo, 2009:9).

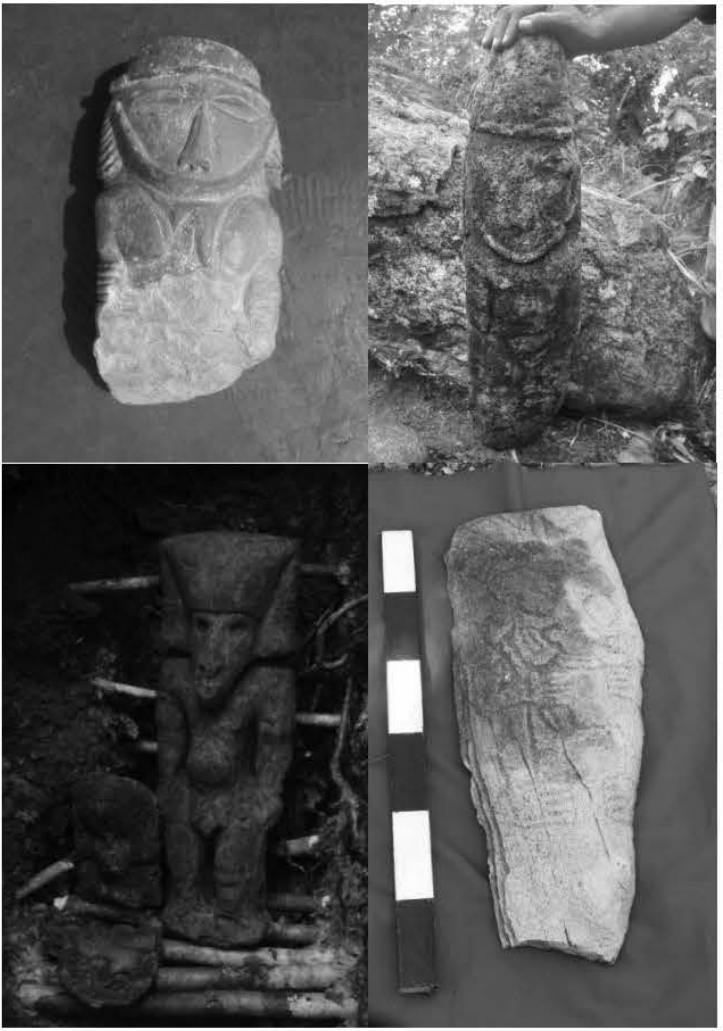

Gambar 11. Arca megalitik di Situs Kali Kubu Srum, Kampung Tua Yasodi, Kali Mimio, dan Srobu (dokumentasi Balai Arkeologi Jayapura)

\section{Batu Peringatan}

Temuan batu peringatan di Situs Hitigima, Distrik Asotipo, Kabupaten Jayawijaya yaitu sebuah bongkah batu alam yang berukuran besar dan tertanam ke tanah. Batu tersebut merupakan bukti atau tanda kedatangan nenek moyang kelompok suku Hubula yang ada di wilayah Hitigima. Batu tanda peringatan ini juga sebagai petunjuk bahwa nenek moyang mereka datang dari wilayah selatan, yang telah menempuh perjalanan jauh hingga tiba di wilayah pegunungan. Lokasi batu peringatan ini berada dalam satu kompleks dengan batu asah (heleb yage matuke) maupun jalan arwah (mokat ake) (Djami, 2015: 16). 


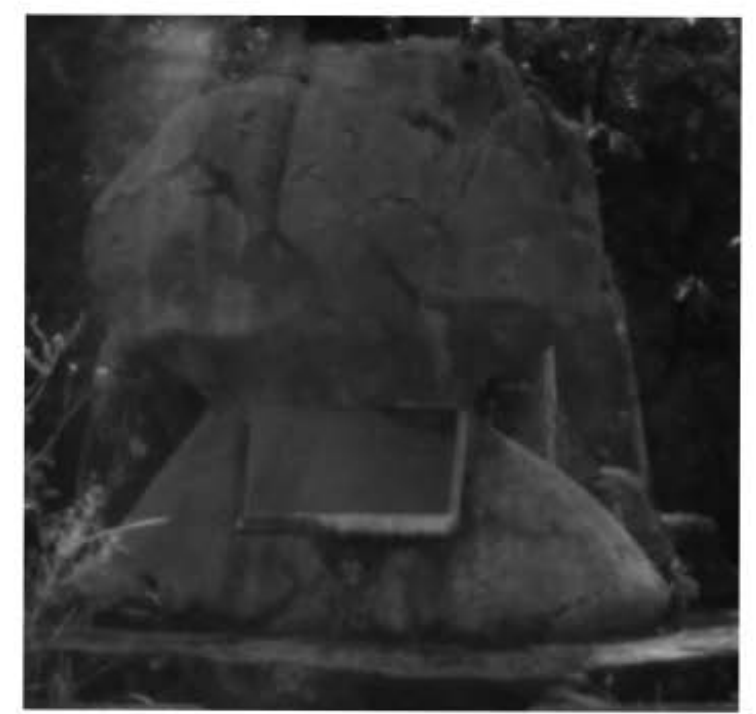

Gambar 12. Batu Peringatan di Situs Hitigima (dokumentasi Balai Arkeologi Jayapura)

\section{Tahta batu}

Di Situs Borumbou, Pulau Adi, Kabupaten Kaimana, telah ditemukan sebuah tahta batu yang terbuat dari susunan batu-batu karang berbentuk persegi, dengan panjang $380 \mathrm{~cm}$, lebar $270 \mathrm{~cm}$, dan tinggi $70-80 \mathrm{~cm}$. Tahta batu tersebut menurut ceritera masyarakat adalah sebagai tempat duduk raja ketika melakukan pertemuan dengan rakyatnya (Mas'ud, 2014: 34-35).

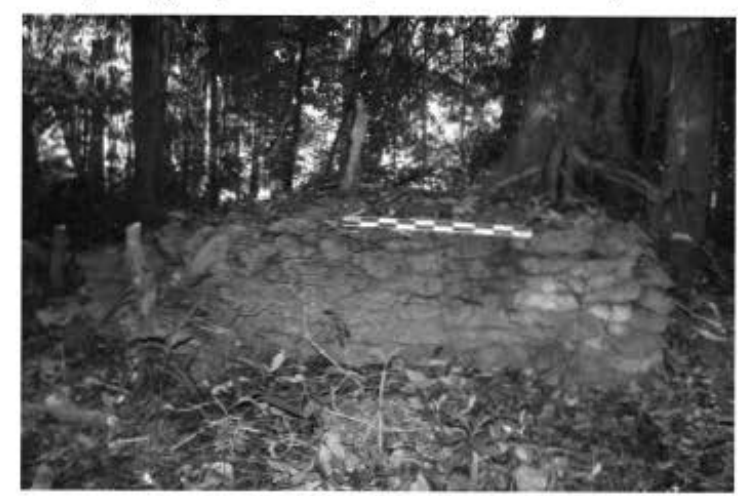

Gambar 13. Tahta Batu di Situs Borumbou dokumentesi Balai Arkeologi Jayapura)

\section{Menhlr}

Temuan menhlr dl wlayah Papua cukup banyak, dan umumnya berupa batu-batu alam berbentuk lonjong dengan memiliki permukaan halus dan juga kasar tidak beraturan, serta ada Juga menhlr darl stalakmlt' pilar yang insitu dalam gua. Menhir- menhir tersebut ada yang mumi batu alam dan juga telah mendapat campur tangan manusia dalam pengerjaanya, seperti temuan batu perang di Situs Pulau Mantai, Kampung Kwadeware, Distrik Waibu, Kabupaten Jayapura, yaitu berupa temuan dua buah menhir yang berada dalam posisi melintang dan berdekatan, namun salah satunya dalam kondisi patah. Pada permukaan kedua menhir tersebut terdapat lubang-lubang kecil yang diakibatkan oleh hentakkan unjung-ujung tombak dari para prajurit perang pada masa lampau, ketika mereka melakukan ritual perang dengan harapan mereka memperoleh kemenangan (Suroto, 2010:14).

Selain itu Juga ditemukan kempleks menhir di Situs Megalitik Tutari, Kampung Doyo Lama, Distrik Waibu, Kabupaten Jayapura, yang berjumlah 110 buah. Menhir-menhir tersebut berupa batu-batu tegak dengan berbagai bentuk dan ukuran, yang didirikan di atas permukaan bukit dengan ditopang oleh beberapa bongkah batu yang berukuran lebih kecll. Kompleks menhlr InI merupakan tempat suci untuk melakukan upacara pemujaan arwah nenek moyang (Prasetyo, 2001:42).

Temuan menhir lainnya adalah dari Situs Kali Raja, Kampung Wawlyal, Kabupaten Raja Ampat, yang berjumlah empat buah dan diletakkan pada undakan kedua dari bangunan berundak. Menhir-menhir tersebut berfungsi sebagai dewa penjaga telur raja yang dlletakkan pada undakan ketiga. Sedangkan temuan menhir di Situs Gua Sosoraweru, Kampung Forir, Distrik Kokas, Kabupaten Fakfak adalah berupa tiang batu pembentukan darl stalakmit. Menhlr Inl dipercaya sebagai lambang nenek moyang dan masih dikeramatkan hingga kini 
(Sukandar dan Mas'ud, 2012: 38 57), bahkan masih dilakukan kegiatan ritual pemberian sesajen untuk mendapat perlindungan, kekuatan, dan pertolongan ketika mereka menghadapi kesulitan hidup (Maryone, 2014: 119).

Temuan menhir lainnya adalah dari Situs Hitigima, Distrik Assotipo, Kabupaten Jayawijaya adalah berupa beberapa batu alam yang berdiri di area dekat jalan arwah. Batubatu tersebut merupakan tempat melompatnya burung kiwiko (burung hitam) ketika upacara penghantaran arwah menuju Wakunoak yaitu tempat bersemayamnya roh-roh orang mati yang terletak di sebuah ceruk yang berada di lereng Gunung Hesagenem. Sedangkan temuan menhir di Situs Gunung Srobu, Kelurahan Abe Pantai, Distrik Abepura, Kota Jayapura adalah sebuah batu monolit yang ditanam dari jenis batu gneis. Menhir ini merupakan simbol nenek moyang dan sebagai sarana pemujaan. Lokasi menhir ini berada dekat dengan dolmen yang berfungsi sebagai altar. Sedangkan posisi menhir lainnya terletak di sebelah barat, dan menhir ini didirkan di atas teras bangunan berundak yang juga berfungsi sebagai sarana pemujaan (Djami, 2015: 88).

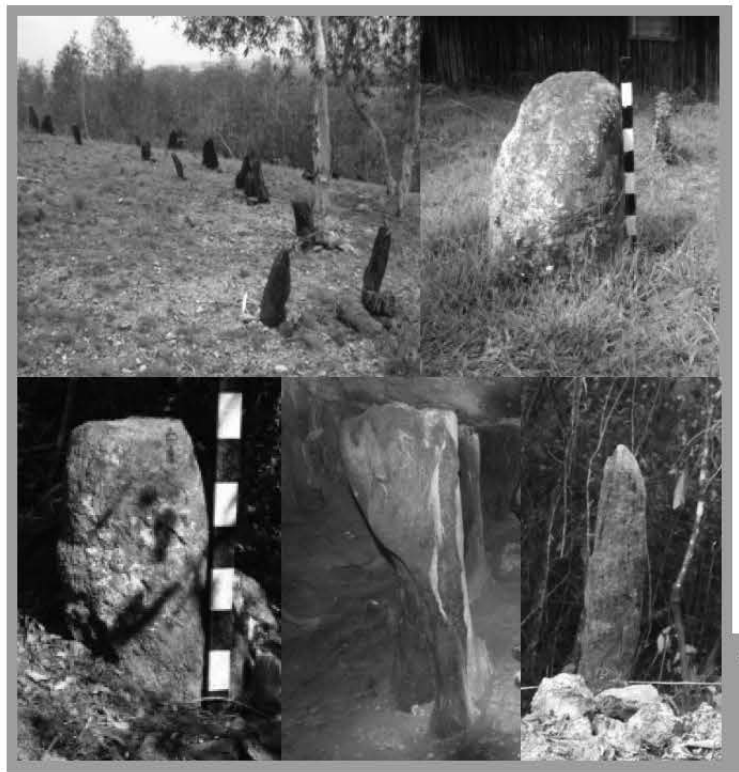

\section{Dolmen (Meja Batu)}

Temuan dolmen di Situs Gunung Srobu, Kelurahan Abe Pantai, Distrik Abepura, Kota Jayapura adalah berupa sebuah papan batu yang ditopang oleh beberapa tiang batu. Dolmen tersebut terbuat dari jenis batu pasir yang digunakan sebagai meja altar untuk pemujaan, hal ini ditunjang keberadaan menhir yang berhadapan dengan meja batu dan area ini dikelilingi susunan batu membentuk lingkaran (Tim Peneliti, 2014: 8). Selain itu juga di temukan sisa dolmen di Situs Marweri Urang, Kampung Kwadeware, Kabupaten Jayapura yaitu berupa sebuah papan batu, dan saat ini masyarakat mengatakan bahwa papan batu tersebut adalah pintu kubur atau makam Marweri nenek moyang mereka (Tim peneliti, 2010:9-10).

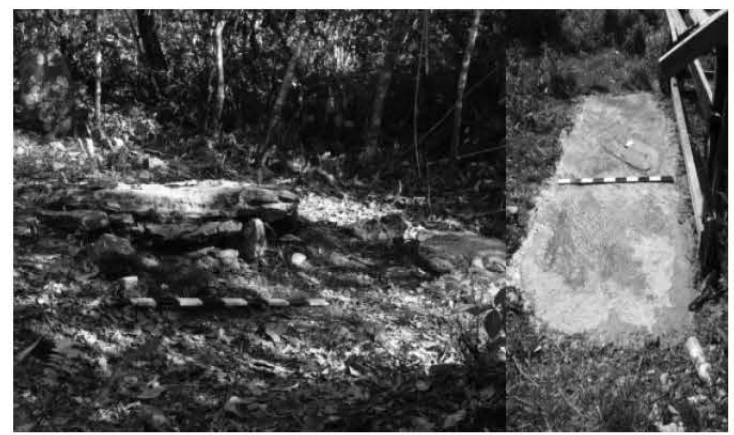

Gambar 15. Kondisi Dolmen di Situs Gunung Srobu (dokumentasi Balai Arkeologi Jayapura)

\section{Batu bergores}

Temuan batu bergores di Situs Megalitik Tutari, Kampung Doyo Lama, Distrik Waibu, Kabupaten Jayapura adalah berupa bongkah-bongkah batu besar, yang pada permukaannya mengandung lukisan yang dibuat dengan teknik gores. Lukisan-lukisan tersebut berupa gambar manusia, ikan, kura-kura, ular, kadal/biawak, burung, flora, kapak batu, rantai/gelang-gelang, dan geometris. Lukisan-lukisan ini

Gambar 14. Menhir di Situs: Megalitik Tutari, Hitigima, Gunung Srobu dan Gua Sosoraweru (dokumentasi Balai Arkeologi Jayapura) 
memiliki makna seperti lukisan manusia yang dikaitkan sebagai gambar nenek moyang yang memiliki kekuatan magis, lukisan hewan seperti ikan dan kurakura sebagai hewan air dalam konteks danau sentani yang dikaitkan dengan kontak magis religius, dan juga terkait dengan menghasilkan buruan yang banyak, serta lukisan biawak yang lebih dikaitkan sebagai penjelmaan roh nenek moyang dan juga sebagai lambang kekuatan magis, lukisan flora terkait dengan kesuburan tanaman, lukisan kapak batu terkait dengan peralatan untuk mendapat hasil memuaskan, dan lukisan geometris yang melambangkan gunung tempat bersemayamnya roh nenek moyang, dan matahari sebagai lambang kehidupan (Prasetyo, 2001: 7-40). Objek-objek lukisan tersebut memiliki bentuk yang natural dan bermakna komunikatif maupun inspiratif.

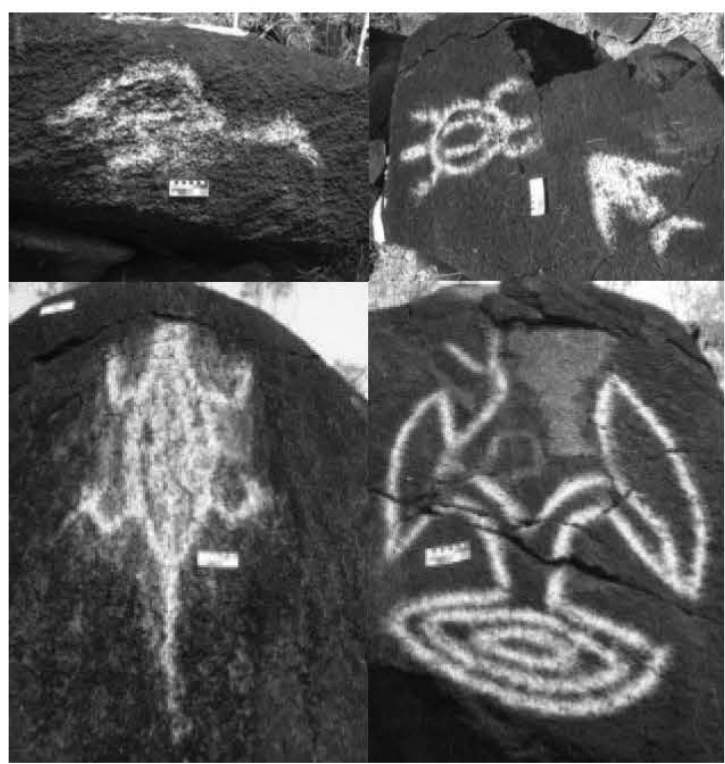

Gambar 16. Beberapa Motif Lukisan Batu di Situs Megalitik Tutari (dokumentasi Erlin)

\section{Pahatan Batu}

Temuan pahatan batu di Kabupaten Biak Numfor terdapat di Situs Gua Yenukem, Situs Gua Kufrai dan Situs Gua Abi di Desa Makmakerbo, Distrik Oridek. Temuantemuan tersebut merupakan seni cadas yang dibuat dengan teknik pahat pada bongkah-bongkah batu, maupun maupun pada dinding-dinding gua. Yang objek seninya berupa gambar orang, patung karwar, ular, perahu, kadal, dan wadah. Adapun makna lukisan di Situs Gua Yenukem dan Situs Gua Kufrai adalah terkait dengan suatu upacara inisiasi atau pentahbisan generasi muda menjadi dewasa sehingga layak dalam adat serta penyatuan dengan leluhurnya. Sedangkan di Situs Gua Abi adalah terkait dengan suatu perjalanan, keadaan lingkungan dan kehidupan sosial budaya masyarakatnya (Djami, 2011: 69-70).

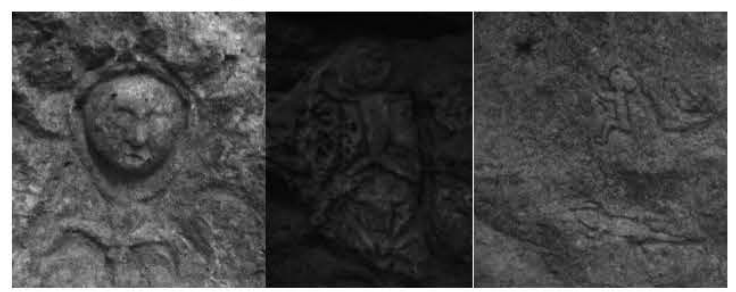

Gambar 17. Seni pahat dari Situs Gua Yenukem, Gua Kufrai dan Gua Abi, Biak Timur (dokumentasi Balai Arkeologi Jayapura) Totor

Temuan totor di Situs Kampung Lama Kombif, Kampung Suswa, Distrik Mare, Kabupaten Maybrat. Totor merupakan tempat keramat atau tempat bersemayam roh orang mati. Lokasi totor umumnya berada di atas bukit maupun di dalam hutan. Bentuk totor cukup bervariasi sesuai dengan klen yang memilikinya, seperti totormilik marga Nauw dan marga Bamero yaitu berupa sejumlah batu yang ditanam ke dalam tanah dekat pohon besi dan juga terdapat sobekan-sobekan kain merah yang diikat pada batangnya. Menurut masyarakat, totor sebagai tempat menghias arwah dan tempat menaruh barang-barang kesayangan milik si mati semasa hidupnya (Fairyo, dkk 2014:11-12). 


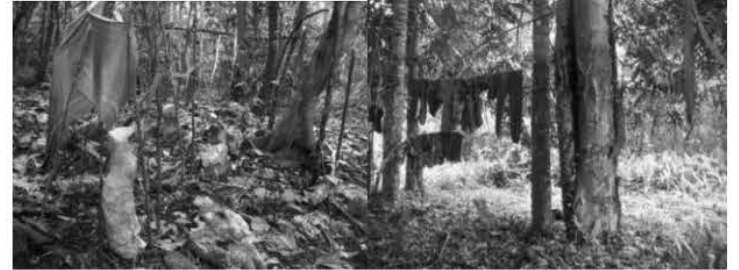

Gambar 18. Totor Marga Nauw dan totor Marga Bamero di Situs Kampung Lama Kombif (dokumentasi Balai Arkeologi Jayapura)

\section{Batu Teteruga/Penyu atau Lensau Fatiafo}

Temuan batu teteruga di Kampung Bagaiserwar, Distrik Sarmi Kota, Kabupaten Sarmi adalah sebuah batu monolit yang terletak di pesisir pantai. Batu tersebut merupakan batu pasir berwarna hitam keabuan dengan panjang $160 \mathrm{~cm}$, lebar $140 \mathrm{~cm}$ dan tebal $70 \mathrm{~cm}$, bagian permukaan batu cukup datar dan terdapat lubanglubang bulat di atasnya. Batu ini dipercaya oleh masyarakat Suku Sobei sebagai teteruga atau penyu yang berubah wujud menjadi batu, dan batu ini juga dipercaya sebagai objek yang mendatangkan rejeki teterugal penyu saat mencari, yaitu dengan cara memecahkan sedikit bagian dari batu tersebut untuk dibawa serta dalam aktivitas pencarian teteruga sehingga nantinya mereka akan berhasil. Konon ukuran batu tersebut cukup besar dan bentuknya seperti penyu/teteruga, namun karena sering dipecahkan maka ukurannya menjadi lebih kecil seperti yang tersisa sekarang ini.

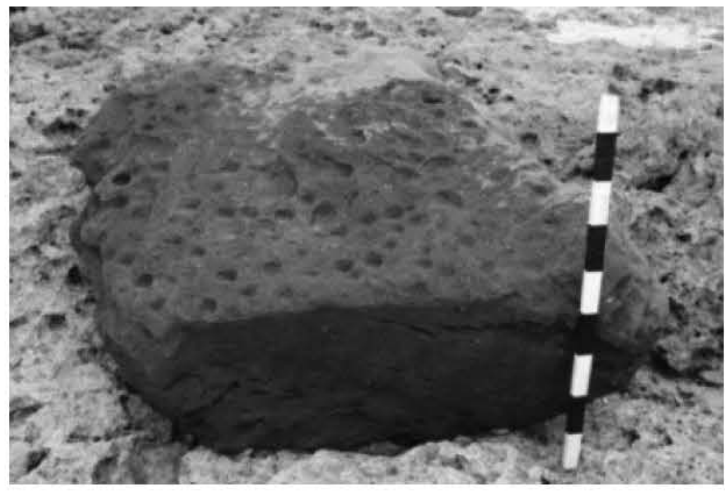

Gambar 18. Batu teteruga di Situs Kampung Bagaiserwar (dokumentasi Balai Arkeologi Jayapura)

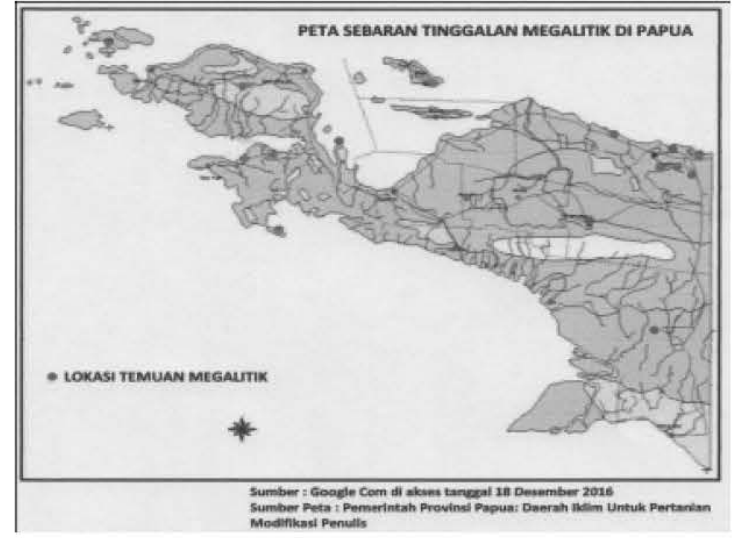

Keragaman bentuk tinggalan budaya tersebut dapat dikelompokkan ke dalam budaya megalitik, yaitu selain objeknya yang terbuat dari batu, juga karena latar belakang pendiriannya dan sejarah keberadaannya, yang terkait dengan kepercayaan kepada roh nenek moyang dan kekuatankekuatan yang ada di alam semeta, seperti diketahui bahwa dalam konsep kepercayaan megalitik selain dalam konteks hubungan dengan pemujaan terhadap nenek moyang (Wagner, 1959:23-25; dalam Prasetyo, 2015: 1516), juga kepada kekuatan-kekuatan alam yang dahsyat (Sutaba 2008: 90).

Namun demikian, diketahui pula bahwa telah ada perkembangan dalam pendirian objek megalitiknya, seperti kehadiran objek batu teteruga yang terkait dengan memperoleh rejeki binatang penyu. Perkembangan tersebut diilhami dari kehidupan sehari-hari, seperti yang tercermin dalam kehidupan beberapa kelompok masyarakat Papua yang telah menjadikan sejumlah benda-benda alam, baik itu binatang maupun tumbuhan sebagai totem klennya, hal ini terkait dengan kekuasaan dan berkat dari totem dimaksud. Selain itu, diperoleh suatu gambaran bahwa budaya tersebut pada waktu lampau berkembang cukup pesat, yang terlihat pada keragaman bentuk megalitik yang menggambarkan berbagai aspek kehidupan manusia, seperti aspek sosial, ekonomi, religi dan kebudayaan sebagai wujud keseimbangan serta keselarasan dengan alam semesta. 
Dalam aspek sosial religi dapat dipahami bahwa adanya temuan bangunan megalitik yang berbentuk bangunan berundak, menhir, arca megalitik, batu beranak, batu rejeki, jalan arwah, batu temugelang, dolmen, pahatan batu, batu bergores, dan totor yang berada di beberapa tempat di wilayah Papua, ternyata di dalamnya terkandung konsep-konsep kepercayaan berkait kehidupan sosial dalam komunitas tertentu yang dibangun secara bergotong royong, karena memiliki kepentingan bersama, dan menyatu dengan alam lingkungan sekitarnya serta kehidupan setelah mati. Bahkan pada beberapa objek seperti arca magalitik dan menhir, merupakan simbol nenek moyang dan sebagai sarana pemujaan.

Sedangkan dalam aspek ekonomi dan kebudayaan tercermin pada pendirian bangunan megalitik berbentuk batu rejeki, batu beranak, batu sukun, tiang batu, batu asah, batu peringatan, batu teteruga dan batu temugelang, yang keberadaanya tidak terlepas dari usaha peningkatan

\section{PENUTUP}

Temuan tinggalan megalitik di wilayah Papua cukup beragam bentuknya yaitu berupa punden berundak, batu rejeki, tiang batu, batu beranak, lumpang batu, batu asah, jalan arwah, jajaran batu, batu temugelang, arca megalitik, batu peringatan, tahta batu, menhir, dolmen, batu bergores, pahatan batu, totor, dan batu teteruga. Dari bentuk-bentuk megalitik tersebut, diketahui ada beberapa di antaranya seperti arca-arca megalitik merupakan produk luar, atau benda-benda tersebut dibawa dari luar Papua, yang mungkin masuk ke wilayah Papua bersamaan dengan kedatangan manusia pendukungnya atau sebagai hasil pertukaran. Sedangkan tinggalan kesejahteraan yang berlandaskan corak budaya dan keadaan lingkungan alam sekitarnya, yang terbentuk sebagai bagian dari kearifan lokal (local wisdom) sekaligus menjadikan gambaran kehidupan manusia, kebudayaan, dan lingkungan yang berkembang hingga kini.

\section{Kehadiran beragam bentuk} budaya megalitik tersebut sebagai akibat terjadinya kontak budaya antara Austronesia dan Melanesia, yang mana kedua bangsa tersebut samasama memiliki konsep kepercayaan kepada roh nenek moyang, namun pada bangsa Melanesia konsep kepercayaannya lebih abstrak (tanpa artefak), sedangakan pada bangsa Austronesia konsep kepercayaanya cenderung lebih konkrit (dengan artefak). Bertemunya kedua bangsa tersebut telah mengakibatkan konsep kepercayaan kepada roh nenek moyang di wilayah Melanesia Papua menjadi berwujud sebagai proses komplementer seperti yang terlihat pada tinggalan-tinggalan megalitik yang ada di Papua.

megalitik lainnya, merupakan produk budaya Papua yang dihasilkan sendiri oleh manusia pendukungnya, yaitu ketika kelompok-kelompok tersebut telah eksis di wilayah ini, sehingga merekapun mulai melanjutkan tradisi yang dimilikinya dengan mendirikan bangunan megalitik sesuai dengan konsep kepercayaan sekaligus untuk memenuhi kebutuhan sosial religinya. Ini mengingat bahwa dalam tujuan pendirian bangunan megalitik bukan hanya untuk kepentingan pribadi tetapi lebih kepada kepentingan kelompok. 


\section{DAFTAR PUSTAKA}

Djami, Erlin Novita Idje. 2011. "Seni Cadas di Wilayah Biak Timur". Jurnal Papua TH. III No.1 Juni. Balai Arkeologi Jayapura.

Djami, Erlin Novita Idje. 2015. "Penelitian Kawasan Terpadu Situs Gunung Srobu, Kelurahan Abepantai, Distrik Abepura, Kota Jayapura". Laporan Penelitian Arkeologi. Balai Arkeologi Jayapura.

Djami, Erlin Novita Idje. 2015. “Penelitian Peradaban Manusia di Kawasan Lembah BalimSelatan, Kabupaten Jayawijaya". Laporan Penelitian Arkeologi. Balai Arkeologi Jayapura.

Fairyo, Klementin. 2013. "Eksplorasi Arkeologi di Kawasan Pulau Terluar (PulauMeosbefondi dan Pulau Mapia), Distrik Supiori Barat, Kabupaten Supiori, Provinsi Papua". Berita Penelitian Arkeologi No. 11. Balai Arkeologi Jayapura. HIm. 50-92.

Fairyo, Klementin, Zubair Mas'ud, dan Sri Chiirullia Sukandar. 2014. "EksplorasiPeninggalan Arkeologi dan Etnoarkeologi di Distrik Mare, Kabupaten Maybrat, Provinsi Papua Barat". Laporan Penelitian Arkeologi. Balai Arkeologi Jayapura.

Fairyo, Klementin, Erlin Novita Idje Djami, dan Amurwani Putri. 2015. "PenelitianTinggalan Tradisi Megalitik di Kokas, DistrikAifat Barat, Kabupaten Maybrat". Laporan Penelitian Arkeologi. Balai Arkeologi Jayapura.

Kawer, Sonya Martha. 2014. "Eksplorasi Arkeologi di Distrik Bomakia, Kabupaten BovenDigoel". Berita Penelitian Arkeologi Nomor 12. Balai Arkeologi Jayapura. HIm. 1-41.

Mansoben, Johszua Robert. 1995. Sistem Politik Tradisi di Irian Jaya. Seri LIPI Rul 5. Jakarta.

Mas'ud, Zubair. 2014. "Penelitian Perkembangan Sejarah Peradaban Manusia dari MasaPrasejarah Masa Sejarah di Kabupaten Kaimana". Laporan Penelitian Arkeologi. Balai Arkeologi Jayapura.

Maryone, Rini. 2014. "Megalitik dan Ceritera Rakyat Suku Baham di Gua Sosoraweru, Fak-Fak". Jurnal Papua. Vol.6 Edisi No.2 November. Balai Arkeologi Jayapura.

Mene, Bau. 2013. "Penelitian Arkeologi Distrik Yokari dan Distrik Depapre, KabupatenJayapura". Laporan Penelitian Arkeologi. Balai Arkeologi Jayapura.

Prasetyo, Bagyo, D. D. Bintarti, Dwiyani Yuniawati, E. A. Kosasi, Jatmiko, Retno Handini,E. Wahyu Saptomo. 2004. Religi pada Masyarakat Prasejarah di Indonesia. Jakarta:Proyek Penelitian dan Pengembangan Arkeologi.

Prasetyo, Bagyo. 2009. "Sebaran Situs Megalitik Bondowoso: Tipe dan Karakteristiknya". AMERTA. Jurnal Penelitian dan Pengembangan Arkeologi Vol.27 No. 1. Pusat Penelitian dan Pengembangan Arkeologi Nasional. HIm 1-15. 
Prasetyo, Bagyo. 2001. "Pola Tata Ruang dan Fungsi Situs Megalitik Tutari, KecamatanSentani, Kabupaten Jayapura, Provinsi Irian Jaya". Berita Penelitian Arkeologi No.03. Balai Arkeologi Jayapura.

Prasetyo, Bagyo. 2015. Megalitik Fenomena yang Berkembang di Indonesia. Jakarta: Pusat Penelitian Arkeologi Nasional kerjasama Penerbit Galangpress.

Simanjuntak, Harry Truman. 2010. "Penutur dan Budaya Austronesia" dalam Arkeologilndonesia dalam Lintasan Zaman. Jakarta: Pusat Penelitian dan Pengembangan Arkeologi Nasional. HIm 41-7.

Soejono, R. P. dan R. Z Leirissa (Ed.). 2010. Sejarah Nasional Indonesia I ZamanPrasejarah di Indonesia. Edisi Pemutakhiran. Jakarta: Balai Pustaka.

Sukandar, Sri Chiirullia, dan Zubair Mas'ud. 2012. "Ekskavasi Situs Gua Sosoraweru di Distrik Kokas, Kabupaten Fakfak, Provinsi Papua Barat". Berita Penelitian Arkeologi Nomor 10. Balai Arkeologi Jayapura. HIm. 30-76.

Sukendar, Haris. 1987. "Konsep-Konsep Keindahan pada Peninggalan Megalitik" dalam Estetika dalam Arkeologi. DIA II. Jakarta: Pusat Penelitian Arkeologi Nasional.

Suroto, Hari, Erlin N. I. Djami, M. Irfan Mahmud. 2011. "Ekskavasi dan Survei Arkeologi diKawasan Danau Sentani". Laporan Penelitian Arkeologi. Balai Arkeologi Jayapura.

Susatyo, Doni Sugio Budi. 1993. "Punden Berundak di Jawa Barat. Tinjauan Atas BentukDenah". Skripsi SarjanaArkeologi, Fakultas Sastra UGM, Yogyakarta.

Sutaba, I Made. 2008. "Teori Dewa Surya dari W. J. Perry Sebuah Catatan" dalamPrasejarah Indonesia dalam lintas Asia Tenggara-Pasifik, Gunadi Kasnowihardjo dan Sumijati Atmosudiro (ed.). Asosiasi Prehistorisi Indonesia dan Fakultas Sastra UGM. HIm. 88-92.

Tim Peneliti. 2010. "Penelitian Arkeologi Prasejarah di Sentani". Laporan PenelitianArkeologi. Balai Arkeologi Jayapura.

Tim Peneliti. 2014. "Eksplorasi Arkeologi di Situs Gunung Srobu, Desa Abe Pantai, DistrikAbepura, Kota Jayapura". Laporan Penelitian Arkeologi. Balai Arkeologi Jayapura.

Triwurjani, Roro. 2006. "Ritus Upacara Pemujaan Tradisi Megalitik Berdasarkan AnalisisPola Fitur dan Artefak Situs Pugungharjo Lampung" dalam Arkeologi dari lapangan ke permasalahan. Edy Sedyawati (ed.). IAAI Komda JabarBanten. 